\title{
Chronic Illness
}

http://chi.sagepub.com/

\section{Social networks, social capital and chronic illness self-management: a realist review}

Ivaylo Vassilev, Anne Rogers, Caroline Sanders, Anne Kennedy, Christian Blickem, Joanne Protheroe, Peter Bower, Sue Kirk, Carolyn Chew-Graham and Rebecca Morris

Chronic IIIness 2011 7: 60 originally published online 4 October 2010

DOI: $10.1177 / 1742395310383338$

The online version of this article can be found at:

http://chi.sagepub.com/content/7/1/60

\author{
Published by: \\ (9)SAGE \\ http://www.sagepublications.com
}

Additional services and information for Chronic IIIness can be found at:

Email Alerts: http://chi.sagepub.com/cgi/alerts

Subscriptions: http://chi.sagepub.com/subscriptions

Reprints: http://www.sagepub.com/journalsReprints.nav

Permissions: http://www.sagepub.com/journalsPermissions.nav

Citations: http://chi.sagepub.com/content/7/1/60.refs.html

>> Version of Record - Mar 11, 2011

OnlineFirst Version of Record - Oct 4, 2010

What is This? 


\title{
Social networks, social capital and chronic illness self-management: a realist review
}

\author{
IVAYLO VASSILEV ${ }^{\star}$, ANNE ROGERS ${ }^{\star}$, CAROLINE SANDERS $^{\star}$, \\ ANNE KENNEDY*, CHRISTIAN BLICKEM ${ }^{\star}$, JOANNE PROTHEROE*, \\ PETER BOWER ${ }^{\star}$, SUE KIRK $^{\dagger}$, CAROLYN CHEW-GRAHAM* and $^{\star}$ \\ REBECCA MORRIS* \\ ${ }^{\star}$ Health Sciences Research Group - Primary Care, School of Community Based Medicine, \\ University of Manchester, UK \\ ${ }^{\dagger}$ School of Nursing, Midwifery and Social Work, University of Manchester, UK
}

Received 29 April 2010, Accepted 20 fuly 2010

\begin{abstract}
Background: Existing literature on the design of interventions and health policy about self-management have tended to focus on individual-centred definitions of self-care and there is growing recognition of the need to extend consideration beyond individual factors, which determine self-care, to examine wider influences such as the health service, the family and the wider social context.

Aims: To explore the theoretical and empirical links between social networks, social capital and the self-care practices associated with chronic illness work and management in the context of people's everyday lives.

Method: A realist review method was used to search and appraise relevant quantitative and qualitative literature. Findings: The review findings indicate that social networks play an important part in the management of long-term conditions. We found that social networks tend to be defined narrowly and are primarily used as a way of acknowledging the significance of context. There is insufficient discussion in the literature of the specific types of networks that support or undermine self-care as well as an understanding of the processes involved. This necessitates shifting the emphasis of self-care towards community and network-centred approaches, which may also prove more appropriate for engaging people in socially and economically deprived contexts.
\end{abstract}

Keywords: Illness work, Inequalities, Long-term conditions, Social capital, Social networks

\section{INTRODUCTION}

Self-care ${ }^{\mathrm{a}}$ and the promotion of long-term condition management (LTCM) are aspirations within health policy which includes a focus on the delegation of illness work to patients in an attempt to manage demand on health services and provide a better means of managing chronic illness. ${ }^{b}$ While social

Reprint requests to: I Vassilev.

Email: ivaylo.vassilev@manchester.ac.uk networks are in theory recognized as relevant to supporting self-care in practice, the design of long-term condition self-management interventions has given little more than a passing wave to social context, and the role of others in shaping and supporting self-care practices, producing resources relevant to supporting self-care or in identifying points where health inequalities might be perpetuated or ameliorated. ${ }^{1}$

Self-care initiatives have in recent years sought to engage patients in the 
management of their own condition through a number of means. There has been a focus on providing information, developing empowerment and joint decision making at the interface with health professionals. There has also been a focus on improving professional-patient communication and developing self-efficacy. ${ }^{2-5}$ While such foci are highly relevant for engaging individuals in LTCM, arguably these factors have a relatively limited role to play in comparison to the accessing of resources and the organization of everyday life and relationships outside of formal healthcare settings. Moreover, the development and implementation of effective and appropriate selfmanagement strategies require an appreciation of the dynamic between the two key fields of illness management work: the consultation and the patient world. The narrower agenda of self-care orientated to individualistic outcomes has meant that analysis of self-care has been relatively divorced from a body of literature in the last 30 years, which has focused on the role of social networks, lay referrals, stigma, processes of normalization, and the types of illness-related work involved in LTCM. At times, these have been wheeled out to draw attention to the wider context within which people manage and experience chronic illnesses, but, while acknowledged as relevant, they remain underexplored, underdeveloped and therefore limited in their application.

The focus of this review is on furthering the understanding and developing the contribution of notions of social networks and social capital to self-management for longterm conditions. The intention is to offer a critique and platform through which a broader agenda for health research could be developed. We argue that theoretical and empirical work on social networks and social capital has a role to play in offering a more specific socialized understanding of the process of LTCM, and in demonstrating the significance of social context for self-care and its role in addressing inequalities in the management of long-term conditions. ${ }^{6}$ In terms of implementation, this approach offers the conceptual underpinnings for the possibility of developing 'upstream' community or population-based interventions presenting a contrast with the predominant individual-centred behavioural approach to self-management interventions. ${ }^{7}$ Confining 'evidence-based' assessment to individualized interventions tends to disregard those that might address root causes, ${ }^{7}$ and lead to interpretations that hold individuals responsible for their poor health (and thus not acknowledging microand macro-structural influences on health). However, it is also important to avoid a form of social determinism, where the causes and solutions to poor health could be deemed reducible to a 'lack of social capital' and/or to 'poor networks'. ' The aim of a more socialized understanding of LTCM is not about reframing health inequalities as the inequalities of 'network support' (rather than functional or dysfunctional health behaviours), but is more about using the study of networks as a way of understanding how inequalities with relevance to LTCM are produced and reproduced on the micro-, meso- and macrolevels. This is in order to offer an alternative set of assumptions, perspectives, questions and conceptual frameworks within which problems are defined and answers are sought.

The aim of this article is to explore the theoretical and empirical links between social networks, social capital and the selfcare practices of chronic illnesses within the context of everyday life and with a particular focus on inequalities. This review draws on a realist method in order to address the following questions:

- What are the social networks implicated in LTCM?

- How are different networks implicated and what are their functions?

- How do different networks work, what is specific about them, and what are their properties? 
- For whom do different networks work and in what circumstances?

- Why do they work for some people and not others, why under some circumstances but not others, and what are the underlying mechanisms that are implicated?

\section{A REALIST CRITICAL INTERPRETATIVE APPROACH TO THE REVIEW}

The review draws on critical realist philosophy. ${ }^{8-10}$ Critical realist approaches distinguish between three aspects of the world that co-exist but are distinct-empirical (experiences), actual (events), and real (generative mechanisms). This distinction implies notions of relativity - the same event can be perceived differently, influenced by different mechanisms, or the same underlying mechanism might lead to different events in varying contexts. Rich et al. ${ }^{11}$ argued that improvement in outcomes and patient satisfaction may be achieved through a broader understanding of illness in the social context of patients' lives because patients with comparable disease states have different illness experiences, sometimes motivating behaviours that appeared inconsistent with the management needs of the disease. Consistent with this focus, Scambler ${ }^{12}$ argues for the causal importance of broader social structures for grasping stigma relations that typically interact with other factors such as class and command. According to critical realism, different generative mechanisms are not necessarily equally comparable as they operate on different levels of abstraction, and thus a variety of concepts are necessary to deal with relationships and mechanisms operating on different levels. ${ }^{\mathrm{d}}$ The latter means that the complex relationship between empirical, actual, and real can only be grasped through the development of multiple perspectives, while the ultimate test for conceptual and theoretical developments should be their practical adequacy ${ }^{9}$ for understanding the events or processes under investigation.

In the field of health policy and practice, a realist epistemology has been used for developing a method for the assessment of policy interventions, the evaluation of theory ${ }^{13}$ and for theory building. ${ }^{14}$ The main focus has been explanatory in order to refine programme theory by looking at what works for whom and under what circumstances. Realist synthesis method offers detailed procedural steps, whereby the assumptions of a theory or intervention are identified, individually tested in different contexts, and finally recommendations are made for changes to the design of future interventions. In relation to this review, this is slightly modified in so far as we are starting from a situation in which there is currently no overarching theory or a set of competing theories regarding the relationship between social networks and self-management, and studies rarely make an explicit link between social networks, self- and illness management activities. A broad aim of this review is to interpret the categories under which guiding themes can be summarized (social networks, social capital, support and work) as well as to assess relevant interventions and practice. In this sense, the critical interpretative synthesis approach developed by Dixon-Woods et al. ${ }^{14}$ is appropriate because it encourages a critique of literatures, questions taken for granted, assumptions, methods and concepts, and therefore is relevant where the theorization of evidence in a particular area is nascent and the synthesis focuses on concepts (rather than on the level of the set of theories implied in a specific programme/intervention). Drawing on Noblit and Hare, ${ }^{15}$ Dixon-Woods et al. ${ }^{14}$ distinguish between first-, second- and thirdorder constructs. First-order constructs are those that are in everyday use, second-order constructs are interpretative constructs utilized in the social sciences and applied to first-order concepts and third-order constructs, are synthetic constructs, based on interpretations that build on the 
explanations and interpretations of constituent studies. The process of synthesizing evidence is understood here as developing a 'more insightful, formalized and generalizable ways of understanding the phenomenon'. ${ }^{14}$ In this review, we are drawing primarily on the latter approach; we also slightly depart from it inasmuch as we distinguish between different levels of abstraction on which mechanisms and concepts could operate, thus allowing the synthesis to move simultaneously upwards towards abstract-simple and downwards towards concrete-complex synthesis. This approach is in contrast to focusing exclusively on developing third-order, synthetic, constructs (abstract-simple) because the latter run the risk of overemphasizing the 'field' of the evidence base at the expense of the field of emerging phenomenon under review. The latter point is critical to examples whereas in the case of this review, the existing evidence (quantitative, qualitative and theoretical work) is limited and a large number of important questions have not yet been addressed. Identifying key questions as well as offering intuitive and non-evidencebased explanations and hypothesis could be as, or more important, than the synthesis based on the existing evidence, and is likely to be best suited for meeting the test of practical adequacy. ${ }^{9}$

\section{REVIEW STAGES}

Stage 1 of this review was a scoping search of the literature intended to familiarize the reviewers with the range of relevant literature. At this stage, we selected papers from an existing database on social networks and social capital collected for the purposes of an earlier study. The database contained 2637 papers that had been captured by a structured search strategy (using keywords including 'social networks', 'social capital', 'psychosocial support', 'community-based support', 'chronic illness' and 'chronic disease, ${ }^{\text {e }}$ to search specific databases including
Medline, Web of Science, and Sociological Abstracts) combined with citation searches of key papers identified for the earlier study. IV and AR searched this set for relevant papers for this review. A total of 250 papers were selected. We were looking for key theoretical papers as well as for exemplar empirical studies (studies of mental health were excluded). The abstracts of these papers were selected out for further discussion on the basis of mention of the terms social networks and LTCM. In stage 2 of the review, five further key themes were identified as relevant for subsequent searches to social networks and LTCM: everyday work, stigma, networks of place, patient-doctor interactions and interventions deploying social networks. Further searches were conducted around the two key concepts, social networks and social capital, and these five themes. Initial searches and identification of key papers were conducted by AR. After this stage, further searches were conducted in the Web of Science through keywords (social networks, social capital, chronic illness, diabetes, chronic heart disease (CHD) and chronic kidney disease (CKD)) which returned 499 articles; a further keyword (self-care) search returned further 17 hits and with 'self-management' further 12 hits. Medline returned 209 hits for 'social support', 'diabetes', and 'self-care'; 'social networks', 'diabetes' and 'self-care' returned further 11 hits. After clearing duplicates, 346 hits remained in the database. The same keywords, 'social support', 'diabetes' and 'self-care', 'social networks', 'diabetes' and 'self-care', were used in order to search for papers specifically looking at $\mathrm{CHD}$ and CKD. Another search was conducted around the notions of stigma and exclusion, which returned 133 entries. These were reviewed independently by $\mathrm{IV}$ and $\mathrm{AR}$ and 30 papers were selected for inclusion. Further searches were undertaken through following citations of key papers and additional 75 papers were added. A total of 61 papers were selected for in depth review (Fig. A1). 
The 61 papers selected included theoretical and empirical papers both of which contributed to different aspects of the review (Table A1). The findings of the review are presented in five parts. First, we distinguish between the types of social networks discussed in the selected studies. Second, we discuss the emerging themes around functions of social networks in relation to LTCM. Third, we discuss the properties of social networks. Fourth, we discuss the valance of the different forms of support through social networks. Fifth, we distinguish between different types of LTCM outcomes. Finally, we discuss the findings and offer some conclusions and an agenda for further empirical research.

\section{Defining Types of Networks}

This section is concerned with distinguishing between the types of networks implicated in LTCM. For the purposes of this review, ${ }^{16}$ it offers a useful distinction between social networks and social relationships. This distinction problematizes the extent to which networks resemble a set of dyadic relationships independent from each other (where 'the network' becomes a cumulative reference for the summary of these relationships) or as relationships that have multiple points of connectedness that are not solely mediated by the individual located at the centre. In cases where individual members of the network are interconnected directly (i.e. know each other, meet/get in touch, etc. independently), 'the network' appears to have different properties when compared to an individualized network constituted of dyadic relationships. For example, family members can be viewed as a network constituted by both a set of relationships and group memberships (e.g. friends, colleagues, etc.) that overlap to a different extent. Thus, while both individualized and community-like types of networks are possible, most actual networks would incorporate both elements and in this sense (observed), networks can be better understood as networks of networks.
We can extend the distinction between relationships and networks to a three-way distinction between networks as relationships, affective communities, and networks of networks (or personal communities; see Pescosolido $\left.{ }^{16}\right)$. This three-way distinction broadly reflects the ways in which networks are most frequently used in the reviewed studies, with the only caveats being that 'affective communities' are more broadly interpreted to include a variety of groups with a different degree of cohesion (i.e. the extent to which affective/emotional aspects are important to members of these groups would vary). In the studies that are included for review the notions of 'social networks' and 'social capital' are not always explicitly mentioned. However given that our main focus is not in assessing the use of the notions but rather on understanding the relationships that they stand for. We have included studies where the importance of networks and social capital are implied without being explicitly mentioned.

1. Networks as (dyadic) relationships are central for the majority of the reviewed studies ( $n=44$ studies), which reflect the tendency in the broader literature. Dyadic relationships include relationships between partners, relatives, friends, and neighbours.

2. Networks as affective communities: We can distinguish between three types of social networks as groups or (affective) communities that are discussed in relation to LTCM ( $n=24$ studies). These are first, pre-existing communities that are assumed to be cohesive, primarily associated in the literature with belonging to family, religious or ethnic groups, but also locality or neighbourhood, number, and second, groups that have emerged more recently and are primarily associated with specific interventions or local initiatives. The latter could be further divided into face-to-face groups and virtual forums developed over the internet.

3. Networks of networks (personal communities) are only discussed in seven of the selected studies. 


\section{Functions of Social Networks and the Social Embeddedness of Self-care}

Papers in this review demonstrate that networks are central to the discourses and practices of self-care through: shaping illness knowledge and narratives and shaping and understanding the meaning of normalcy and deviance. This impacts on how illness is managed by others and how individual and group responsibilities are negotiated as well as the making of decisions to look for healthrelevant advice and support from professionals and/or non-professionals.

Shaping Knowledge, Discourses and Narratives What people with LTCs know about an illness and how they talk about it is shaped by others around them. The form and content of illness narratives are constructed within social networks. ${ }^{17,18}$ Furstenberg and Davis ${ }^{19}$ argue that everyday discussions of health problems lead to the transmission to the sufferer of new information about the condition, reinforcement of health actions, and attempts to persuade or intervene directly. Thus, symptoms are not there simply to be evaluated but are the product of and are constituted by the conversations people engage with one another. The most important conversations are those between partners (strong ties). ${ }^{17,20}$ Lay advice is shaped according to distinctive social characteristics, for example influenced by gender, stage in life course, level of intimacy, ${ }^{17}$ disruption to existing networks, existence of chronic rather than acute illness, and the extent of mutual suffering of diseases shared by a sizeable proportion of their peer group. ${ }^{19}$

The role of social networks is also implicated in the way in which knowledges and discourses on chronic illness are mediated by ethnicity, ${ }^{21,22}$ group history, ${ }^{22}$ and through experiences within the family. ${ }^{23}$ In a study of Aboriginal people in Canada, Sunday et al. ${ }^{21}$ argue that there are divergent causal and moral stories for diabetes: biomedical that emphasizes lifestyle and lifestyle change, and traditional that emphasize genetic causes and the need to return to health and purity through traditional knowledge. ScollanKoliopoulos et $a .^{23}$ demonstrate that patients' recollections of experiences of members of their families can affect their own perceptions and behaviour. In a study of white, Pakistani and Indian respondents, Lawton et al. ${ }^{22}$ argue that there were different emphases on the role of external factors and individual responsibility and lifestyle in developing diabetes.

\section{Stigma, and Defining Normalcy and Deviance} The role of others in defining normalcy and deviance has been latent and the main focus in the literature has been on stigma as a personal experience. However, stigma is necessarily construed and experienced in relations with others, and therefore structural social position and social relational elements of stigma are likely to have an impact on how stigma is experienced ${ }^{f}$ and how it co-shapes the everyday practices that are relevant for illness management as well as one's sense of well-being.

Illness management can be affected by stigma through the attribution of personal responsibility for lack of control and/or for poor management. Thus, Lawton et al. ${ }^{22}$ compared white and South Asian respondents with type 2 diabetes and found that whereas South Asian respondents tended to externalize responsibility linking it to migration, white respondents tended to emphasize lifestyle 'choices' and 'personal failings'. 'In a study of patients with lung cancer and their carers, Lobchuk et al. ${ }^{24}$ found that both patients and carers placed the locus of control and cause of disease with the patient, but both patients and carers attributed more negative attributes to themselves and more positive towards their partners. Carers also tended to ascribe more responsibility, fault, and guilt towards the patient. While stigma tends to be associated with broader societal processes, its experience is related to both impersonal and generalized others, but, potentially more importantly, to relationships with significant others. Rogge et al. ${ }^{25}$ 
argued that those who are obese are reminded about this during their everyday encounters with family members, peers, and healthcare providers. Obesity was commonly discussed as a deviation from social norms and those who were seen as obese as inferior to those who were not. Stigma from intimate members of one's social network can be associated with withdrawal from social activities. ${ }^{26}$ Indeed, Gallant et al., ${ }^{27}$ found more negative influences from family than from friends, and found that people with chronic illness were able to talk to work colleagues about their illnesses more easily than talking to family members. Fiori et al. ${ }^{28}$ found that networks where both family and friends were present featured best in terms of psychological health; however, when comparing two 'restricted networks': non-family and nonfriends, depressive symptomatolgy was the highest for individuals in the non-friends network.

\section{Networks and How They Influence the Work Related to LTCM}

The management of LTCs involves the negotiation and co-ordination of arrangements related to the home, family, employment, leisure and friends. Strauss ${ }^{29}$ defines the division of labour as a central question in relation to LTC management, where 'work' is understood as the activities and knowledge that are directly or indirectly relevant for the management of LTCs. ${ }^{\mathrm{h}}$ This involves negotiating individual and group responsibility, and deciding who should do what work, when and how, what Strauss ${ }^{29}$ calls division of rights.

Most of the work related to the management of LTCs is done in the home and is negotiated between family members. This is in terms of the extent to which family practices would change in order to accommodate the needs of the person with the LTC. $^{30}$ Chesla and Chun ${ }^{31}$ in a study of Chinese American families where one of the partners had type 2 diabetes, found that family members were trying to balance the quality of life of the individual with that of the family. This included negotiating disease disclosure, protecting the family's meals, and maintaining ease in family relations despite the symptoms of the illness, while adopting indirect approaches to disagreements. Beaulieu ${ }^{32}$ looked at the meanings of chronic fatigue syndrome to family and friends and argued that significant others weighted the differences of dealing with the chronic illness against the value of the relationship and provided a broad circumvented support rather than outrightly refusing to offer support to sufferers.

Some of the factors that have an impact on the direction of family changes are associated with household structure and configuration (egalitarian or traditional), ${ }^{33}$ the presence (or absence) of family conflict ${ }^{34,35}$ and the expectations associated with specific social roles (especially as related to gender, ${ }^{36,37}$ cultural specificity, ${ }^{31}$ relationship between partners $^{38}$ ).

\section{Relationship Between Health Services and Social Networks}

Symptom management for most people with chronic illness primarily takes place within everyday life. However, it also necessarily involves some degree of interaction with formal healthcare services, making 'illness work' a shared activity between patients and professionals. This shared activity has implications for the construction of meaning as well as the practical management of illness. The need for referral is constituted through conversations with lay others ${ }^{17,39}$ where it can facilitate but also interrupt ${ }^{40}$ or encourage alternative help seeking. ${ }^{41}$

Another element of illness care is related to the ability of patients to understand and transfer the advice of health professionals into their everyday life, as well as being able to explain the specific circumstances of their illnesses within the context of the consultation. While the main emphasis in studies of interaction during consultation has tended to focus on the dyadic physician-patient relationship, a number of studies also recognize that the consultation is often attended 
by a patient companion (triadic) ${ }^{42,43}$ while in other cases, consultations could be between a physician and a group of patients. Within consultations, companions act as mediators in the articulation of concerns and negotiation between doctors and patients and improve each others' understanding. ${ }^{43-46}$ In both cases, the dyadic patient-physician relationship is directly influenced by lay perspectives developed within differently constituted non-professional networks: patient-companion and patient groups. The extent of involvement of both patient and companion was related to age, education and trust in the physician, ${ }^{44}$ while the level of satisfaction of companion involvement has more to do with the right balance and 'getting it just right' than with the actual amount of involvement. ${ }^{47,48}$

\section{Substitutability of Lay and Professional \\ Networks}

Patients with long-term conditions may exhaust what is traditionally available from services and may be reluctant to use services again, while others may consult more in an attempt to resolve their problem. ${ }^{49}$ In contrast, some patients may primarily rely on non-professional sources of information and support, including peers, family friends, and non-medical professionals, and may be reluctant to use formal health services. Illness work is shaped by professional and non-professional networks, which raises possibilities for the substitutability between these different sources; where access to one form of network support is limited or absent, their functions might be provided by alternative means. For example, professionals may in some circumstances be a substitute for the lack of locality networks. Thus, Cocksedge and $\mathrm{May}^{50}$ argued that practitioners can spot and attend (or decide not to) to cues from patients during their interactions. The potential involvement of practitioners could go further extending the 'listening loop" 50 acting as a broker and for facilitating informal social networks. In a study by Adams et al., ${ }^{51}$ professionals were seen as agents able to mobilize locality networks and/or as an aspect of broader social networks providing continuity and links between professional and lay worlds. Befriending interventions make an assumption that professionals can substitute for network and social support though the evidence of this is equivocal. Non-face-to-face interaction over the internet can also act as a substitute to face-to-face social networks although its functions and properties also differ in some important respects. Other alternatives include provision of services by the state ${ }^{52}$ or paying for services.

\section{Properties of Networks}

While distinguishing between the function of networks (previous section) is primarily concerned with establishing the presence of a relationship between networks and specific outcomes, shifting the emphasis towards understanding the properties of networks is an attempt to look comparatively between them. The selected papers allow us to distinguish between networks that have different properties implicating potentially different outcomes for LTCM. These are different depending on whether we focus on relationships, affective communities, or personal communities. In the case of relationships and affective communities, the properties of networks that are likely to be relevant depend on first, the nature of interaction within the dyad/group based on face-to-face, mediated, or anonymous interaction, second, the degree and type of familiarity, friendship, friendliness or intimacy, and third, the degree of pressure to conform to expectations. If we shift the focus towards personal communities, the properties and mechanisms involved are more complex as we also need to take into consideration the attributes of the network (in addition to the properties of its constituent parts).

\section{Properties of Relationships and Affective Communities}

Belonging to an affective community implies the presence of cultural norms and social 
expectations that could prevent a change in lifestyle, ${ }^{22}$ which is enforceable through building consensus in everyday face-to-face encounters. For example, study of British South Asians with diabetes Lawton et al. ${ }^{22}$ shows how social networks can prohibit and/ or facilitate physical activity. Thus, while respondents reported awareness of the need to change their lifestyles, there were practical considerations such as lack of time, or health problems that made physical activity difficult. Such practical issues were interwoven with cultural norms and social expectations that prevented a change in lifestyle.

In contrast, one of the specific properties of virtual communication is that it offers anonymity. Anonymity could be desirable at times of uncertainty ${ }^{53}$ and for groups that are stigmatized. ${ }^{54}$ Thus, Rasmussen et al. ${ }^{53}$ found that young women with type 1 diabetes used internet communication with online networks in order to create stability during life transitions. Women valued their autonomy and being in control of when and to whom they revealed their diabetic status especially during times of uncertainty and life transitions. Thus, access to internet needs to be discussed within the context of other forms of support that are available as well as in terms of the form of interaction that internet use is taking. Active engagement with internet groups is more likely to be associated with a sense of support and well-being than off line support. Seeman ${ }^{54}$ discusses the possibilities (for finding support, information, and advice) that new three-dimensional 'games' imitating real life can offer for patients with chronic conditions, especially for greatly stigmatized chronic health issues such as obesity and mental health. Thus, while participation is usually assumed to be a good thing these examples demonstrate how the properties of different networks can shape the meaning, experience and outcomes of participation so that participation could, under different circumstances (and depending on other intervening mechanisms), lead to isolation, ${ }^{55,56}$ help to overcome isolation or signal (be an expression of) isolation.

Another property of virtual communities is the accessibility of advice (mediated by class ${ }^{57}$ ), and the contextualized advice offered through the shared experience of other participants ${ }^{58}$ (as opposed to the disembedded professional advice, thus resembling to some extent patient-led support groups (e.g. EPP, expert patient programme)). The translation of abstract knowledge into practical knowledge before this knowledge reshapes everyday practices and becomes normalized ${ }^{59}$ as well as the more specific focus on emotional support forms the bases of studies on virtual communities. However, Meier et al. ${ }^{60}$ (2007) and Ravert et al. ${ }^{58}$ report contradictory findings and argue that participation in virtual communities is most relevant soon after diagnosis and of seemingly less value to LTCM in the longer term. This might explain why the use of virtual forums over time does not significantly improve outcomes. $^{61}$

Interaction in virtual forums is sustainable over time in cases when a sense of familiarity is developed between participants, which could be associated with emotional support and the ability to reciprocate (thus making virtual communication resemble more closely the familiarity in face-toface interaction). It is also plausible that emotional support is sought within virtual forums by people who feel isolated due to limited social networks (as well as lack of alternative support which professional networks can sometimes also provide (see section on health services)). Gender differences in the use of internet forums have been reported by Ravert et al. ${ }^{58}$ and Seale et al., ${ }^{62}$ while Loader et $a l .{ }^{57}$ found that improved outcomes were mainly associated with well-informed participants, who routinely used the media, which suggest that social class is an important factor that could account for differences in the use of internet forums. 
Properties of Personal Communities

Only one of the studies in this review, Gallant et al., ${ }^{27}$ discussed the properties of personal networks within the context of LTCM. Both studies found that the size and the content of the network had an impact on health outcomes. Thus, larger networks and networks where there were both family and friends present reported most favourable outcomes, while small networks and networks where there were only family members involved had the worst outcomes. While these findings are only based on two studies, they confirm the findings of studies that focused on ageing $^{63-65}$ and deprivation. ${ }^{66}$

\section{Valence of Networks: Positive and Negative Aspects of Networks}

Within the context of social capital literature, social networks are often discussed as something $\operatorname{good}^{67}$ although there have been acknowledgement that the notion could also have negative aspects. ${ }^{68,69}$ The articles in this review identified both positive and negative impacts that different social networks could have on LTCM. Thus, while most of the reviewed studies found that partners, family, friends and colleagues/ schoolmates can affect positively LTCM, ${ }^{17,19,30,31,45,70-72}$ there was also evidence for the opposite. ${ }^{22,36,53}$ Rasmussen et $a l^{53}$ also found that interaction with professionals could have a negative effect on LTCM. The evidence in this review is insufficient to conclude unambiguously what is the valance of the relationship between types of relationships and LTCM. This is not surprising and could be anticipated, given the complex nature of inter-personal relationships, especially those with close people. However, there is also an indication that the distinction between positive and negative aspects of support may not be sufficiently able to capture this complexity of relationships. In a study of older women experiencing multiple chronic conditions, Roberto et $a . .^{73}$ found that while appreciative of support from family members, at times the women received more help and advice than they would have liked to. Further, excessive support could also be seen as a problem; ${ }^{27}$ indeed, getting the right amount of support is important in all cases. ${ }^{74}$ In this sense, 'getting it just right' could be a more productive way of conceptualizing positive support (rather than amount of support or an opposition between positive and negative aspects). Getting it just right suggests an engaged approach to support where the amount and nature of work that members of the network do are inter-subjectively negotiated. While this means that more could mean less, it does not necessarily imply that less is more, but rather points at the complexities of empowerment. Entitlement is usually framed in negative terms as an entitlement to not contribute or to contribute less (paired with an expectation from others to do more work and offer more support). Entitlement, however, could also be framed positively, i.e. as an entitlement to contribute or to contribute more. Here socialized work is aimed at enabling contribution while social compromise may require accepting contributions that might be more expensive and less efficient than available alternatives (e.g. it might be faster and easier if I did the cooking myself). The latter aspect of entitlement is particularly evident in the central importance given by people with LTC to the ability to 'give something back' both as a condition for further participation (e.g. in self-help groups) and for their sense of well-being. Thus, the division of rights, or contributive justice, ${ }^{75}$ could pose the question of contribution and entitlement differently by putting the main emphasis either on addressing existing inequalities, or on respecting individual autonomy, sense of self-esteem and social worth. ${ }^{i}$

\section{Outcomes of LTCM}

The predominant number of the reviewed studies defined outcomes in relation to professionally defined priorities such as health behaviours $(n=45)$ and bio-medical indicators $(n=12)$, and less so in relation to 
patient-centred outcomes such as happiness and well-being $(n=26)$. While such outcomes are not necessarily contradictory, there are obvious tensions between different objectives and priorities. This is particularly evident in relation to the emphasis on change in lifestyle which implies a change in wellestablished routines that are highly embedded into the practices of everyday life, are an aspect of individual and group identities, and are also embodied and a part of one's habitus. $^{\text {j, } 76}$

\section{Summary of Findings}

The findings of the review are represented in Fig. 1. The main thrust of the reviewed literature is on relationships that are represented in the left-hand side of the figure and those run primarily from top-to-bottom linking dyadic relationships and group membership to professionally defined objectives while demonstrating the importance of context in a general sense. Links between more complexly defined networks and objectives defined in relation to everyday life, as well as links between types of networks and the recursive relationship between professionally centred and everyday-centred objectives (left-right on the diagram) are less frequent.

This review demonstrates that the use of networks in relation to networks as relationships and as affective communities is well represented in most of the papers reviewed and it is well demonstrated that self-care is socially embedded; however the uses of the network notion in to signify networks of networks or personal communities is patchy (only discussed in seven of the reviewed papers). Discussions of social networks, social capital and the involvement of others with LTCM is extensively used in order to question the dominant paradigm, but without offering a well-developed alternative. Thus, while the dominance of professional concerns and definitions, and individual-(rather than community)-centredness, is widely recognized as a problem, most of the literature on LTCs operates within a conceptual and (to a lesser extent) thematic framework that is professional-individual-centred. In this sense,

\section{Social networks: dyadic relationships}

Social networks: affective communities
Social networks: networks of networks
Functions

- Shaping knowledge, discourses and narratives

- Stigma and defining normalcy and deviance

- Networks and how they influence the work related to LTCM

- Relationship between health services and social networks

- Substitutability of lay and professional networks
Properties: dyadic relationships and affective communities

- Familiarity, friendship, friendliness, intimacy

- Face-to-face, mediated, anonymous - Level of expectations and pressure to conform
Properties: networks of networks

- larger networks associated with better health outcomes than smaller ones

- networks where there are both family and friends are associated with better outcomes than family only networks
Valence of networks: positive and negative effects on LTCM

Professionally centred objectives: bio-medical indicators, health behaviours
Valence of networks: balanced support and 'getting it right'

FIG. 1. Summary of findings. 
the potential of the notion of social networks is not sufficiently developed. The latter requires further unpacking of the types of networks involved, as well as the better understanding and conceptualizing of their properties and the mechanisms through which they are shaping actual LTCM practices and discourses.

Coming back to the five key questions, which we wanted to address in the beginning of this article, we could argue that it is only the first, what social networks are implicated in LTCM, and the second, how are different networks implicated, and what are their functions, of these questions that could be answered through this review. The third question, how do different networks work, what is specific about them and what are their properties, could only be partially answered, while the reviewed literature could not offer sufficient answers to the last two questions, for whom do different networks work and in what circumstances, and why do they work for some people and not others, why under some circumstances but not others, and what are the underlying mechanisms that are implicated?

\section{DISCUSSION AND CONCLUSIONS}

In this review, we drew on critical realist approaches in order to define the objectives, method and analysis of the review. We distinguished between types of networks and identified functions and properties of networks in relation to LTCM. The focus was on exploring beyond the factors and influences most usually associated with support for self-care to bring into view the way in which relationships with others, particularly in settings that are outside formal healthcare organizations, offer potential for furthering the understanding of shaping the patterns and types of these relationships, how they might be implicated in ameliorating or perpetuating inequalities and how they might be harnessed for developing new chronic illness management support strategies. The review demonstrated that social networks are widely implicated in LTCM through shaping and understanding normalcy and deviance, knowledge and narratives, the locus of individual responsibility, referrals, consultations, and how illness is managed by others. Drawing on the wider literature, it can be argued that LTCM takes place simultaneously in different everyday worlds, where meanings are created inter-subjectively and where the participants share a common, but mostly taken for granted (rather than reflexively evaluated), 'stock of knowledge'. ${ }^{77}$ The latter is both the basis of common understanding and also informs action, and therefore everyday life worlds, where different networks might be implicated, are built around both interpretative frameworks and frameworks for action. More specifically, illness discourses and practices are co-shaped by pre-existing material circumstances and (largely unreflexive) stocks of knowledge, embedded in everyday life as well as by professional knowledge, discourses and (professionally endorsed) ideologies of the self, and by broader ideologies of the self, intimacy, community and responsibility. Justifications for actual choices or states of affairs can operate within different and often contradictory ideologies (e.g. personal responsibility and autonomy from others), and connectedness to and responsibility for individual and collective others (e.g. family members, the state, health professionals, etc.). These are rarely clearly separated, but they co-exist in different combinations within narratives in relation to different situations. LTCs are managed within different, primarily, but not exclusively, non-professional contexts, where relationships are primarily patterned and unreflexive, and therefore considerations about interventions which might help support self-care support may need to consider ways of reflecting on current network interactions and re-negotiating these. More broadly, within open systems changes in existing practices and the introduction of new ones are a process of a complex and 
multi-level negotiation between considering what is desirable to be done, how people talk about this collectively, why it is done in a particular way and how responsibilities are shared. In this sense, when changes are taking place in open systems, the relationship between material and discursive practices as well as the ideological and normative frames within which they are expressed are difficult to separate. This raises questions such as what is 'good' and 'bad' LTCM (e.g. sense of normality in everyday life, wellbeing, good bio-medical indicators, appropriate health behaviours) and what is 'positive' and 'negative' support (how is this related to outcomes)? Whose values are and/or should be implicated? And given the necessarily irreconcilable differences between professionally centred and everyday-centred objectives, how can those be addressed analytically and within policy?

\section{Limitations of the Studies Reviewed}

The studies reviewed here reflect a broader tendency in the literature on health where the notions of social networks and social capital are predominantly used as a way of demonstrating the existence of an important link between health and social contexts. The notion of social networks has been narrowly used within the reviewed papers and is primarily defined as a single or a set of dyadic relationships rather than discussed within the networks (personal communities) of individuals. Social networks are primarily used as a way of acknowledging the significance of the context within which illness management is taking place, yet within what remains predominantly individual-centred and professional-centred perspectives on health. Here, social networks are primarily used as a metaphor for non-professional (as opposed to professionally centred) or informal (as opposed to related to formal institutions) relations (similar to studies on 'lay perspectives', 'lay advisers', etc.). Thus the notion of social networks is either operationalized in a generic sense (everything nonformal) or as a specific form of relationships (e.g. partner, family and friends). These are rarely differentiated sufficiently and compared to each other. Comparisons are primarily in relation to one type of network aspect (e.g. relationship such as family, partner or community, such as ethnic group, for example) and in relation to one aspect of LTCM, and there are only few studies that are looking across types of networks and different aspects of LTCM. This is in addition to LTCM being primarily defined in medical terms, where there is an assumption that health behaviours and biomedically defined priorities (symptoms and measurements) are also the priorities in everyday life (which is clearly not the case).

Other key notions such as 'family' also tend to be used generically which are limited as a heuristic devise for understanding and analysis of LTCM. The predominant assumption about the 'family' is that it is a 'traditional' family, which does not sufficiently address the large number of nontraditional households (cohabiting siblings, friends sharing accommodation, and children living with parents or relatives) or single-person households. More generally, relationships such as family, kin, friends, neighbours and colleagues cannot be easily and unambiguously associated with 'strong' and 'weak' ties, ${ }^{78,79}$ especially when discussed within the context of open systems.

Furthermore, most of the relationships that are explored as aspects of networks: partner, family, friends, and health professionals, are ambiguous and can be either/or, or both positive and negative when assessed within everyday life. More generally, there is a complex nexus between the role of partner, family and friends, positive and negative types of support, availability and acceptability of support, social capital and social debt, stigma and guilt and isolation and selfisolation. The negotiation of boundaries of care can be seen as embodied moral practice where there could be different combinations of blame, stigma, compassion, entitlement, etc. The latter demonstrates the limitations of the conceptual framework, which can only 
capture very extreme scenarios and builds generalizations on narrow and unrealistic premises. What is needed is the development of the notion of 'family', which refer to sets of relationships that could be about 'close' and 'distant' family, between 'actual' and 'potential' carers, and between 'family' as an ideological discourse of intimacy, care and responsibility and as actual sets of relationships.

Thus, while the existing evidence suggests that different types of communities and relationships tend to have affinities with specific functions in the organization of LTCM these could not be explored in much detail due to the limited evidence. Furthermore, while there is evidence that some types of networks could hold similar functions (e.g. isolated individuals could in some cases rely on professional networks to be more closely involved with everyday work), there is little evidence of the specificities and the limits of the substitutability of different types of relationships. The existing literature does not address in much detail such questions, particularly in terms of the affinities between types of networks and the different types of work implicated in LTCM as well as how these change over time and in relation to illness and life-course trajectories. The structure and significance of healthrelevant networks are embedded in and are shaped by the health and social contexts of specific countries as are the specificities of different conditions, and the visibility and stigma attached to the condition and its symptoms. Thus, it is likely that the significance of social networks and or relationship is going to be more important in some institutional and cultural contexts than they are in others. While LTCM network typology and a typology of network change have not been developed at present, a prerequisite of developing such a typology requires a fine-grained understanding of the types of illness-relevant work involved with specific conditions, the different mechanisms implicated in illness management, and the ways in which they interact within different contexts.

\section{Further Research}

The findings from the review, are useful for conceptualizing self-care within community and everyday contexts and exploring whether different configurations of networks are more conducive than others to supporting self-care activities and are important in shifting the emphasis of self-care from individualized, behaviour-based interventions to community and network-centred approaches. The latter may prove more appropriate beneficial in socially and economically deprived contexts. In order to address these questions, we have developed a programme of empirical work where we will draw on social network analy$\operatorname{sis}^{27,28,80-82}$ and define social networks as 'networks of networks'. These have been operationalized using an empirical approach that has been applied to studies of the family, ${ }^{83}$ ageing ${ }^{63,84}$ and friendship, ${ }^{85}$ but has not been applied to self-care of LTCs. Second, we define self-care as consisting of different types of work ${ }^{29,86-88}$ and as being embedded and normalized into everyday life, ${ }^{59}$ which further extends the empirical approach developed by these earlier studies of social networks.

\section{End Notes}

${ }^{a}$ Self-care has been defined as 'the care taken by individuals towards their own health and wellbeing: it comprises the actions they take to lead a healthy lifestyle; to meet their social, emotional and psychological needs; to care for their longterm conditions; and to prevent further illness or accidents'. ${ }^{89}$

${ }^{\mathrm{b}}$ Department of Health. ${ }^{89}$

${ }^{\mathrm{c}}$ An example of the latter might be policy interventions, which focused exclusively on improving connections, building networks or stimulating participation (at the expense of reducing material inequalities). Notwithstanding some of those difficulties, these constructs open a rich conceptual and theoretical field and thus constitute a relevant starting point for unpacking the diverse processes involved in chronic illness self-care. 
${ }^{\mathrm{d}}$ Note that the distinction between empirical, actual and real does not correspond to a distinction used in meta-synthesis where Noblit and Hare $^{15}$ distinguish between first-order (everyday use) and second-order (as used in the social sciences) constructs. This is discussed further in relation to the critical interpretative synthesis.

${ }^{\mathrm{e}}$ Full search strategy available from authors on request.

${ }^{f}$ Though a counter question of interest is the structural position of those doing the stigmatizing which has received little attention.

${ }^{g}$ For a discussion of the predominance of ideologies of individualism in explaining inequalities among low-income rural whites, see Storrs $;{ }^{90}$ for a cultural perspective on individualism and diabetes care for elderly Russian émigrés in US, see Borovoy and Hine $;{ }^{91}$ however, Blaxter ${ }^{92}$ makes the more general point that individuals incorporate both individual and structural elements in their accounts of inequality, these accounts are often contradictory, and they could change over time and apply differently to oneself and other.

${ }^{\mathrm{h}}$ Strauss ${ }^{29,86,88}$ distinguishes between illness work, everyday work, biographical work, ${ }^{87}$ and articulation work. ${ }^{93}$ Illness work 'consists of regimen work, crisis prevention and management, symptom management and diagnostic-related work', while everyday work 'refers to the essentially daily round of tasks that keep the household going'. It includes: housekeeping and repairing; occupational work; marital work; child rearing; sentimental work; and practical and social activities such as eating. ${ }^{88}$ Biographical work could be defined in relation to the self, and is the work related to the reassessment of personal expectations, capabilities and future plans (see also Bury $\left.{ }^{94}\right)$. Articulation work is the ability to deal with contingency and is closely associated with the need to be able to improvise. Here, articulation work refers to the "work that gets things back "on track" in the face of the unexpected, and modifies action to accommodate unanticipated contingencies'. ${ }^{29,95}$

${ }^{\mathrm{i}}$ Contributive justice refers to 'justice as regards what people are expected and able to contribute in terms of work. Complex, interesting work allows workers not only to develop and exercise their capacities, and gain the satisfaction from achieving the internal goods of a practice, but to gain the external goods of recognition and esteem'. ${ }^{75}$ Contributive justice is about allowing and enabling individuals to develop their potential.

ic Habitus refers to those deeply engrained dispositions which are products of socialization, particularly in early life, and which orient individuals at a subconscious level toward the world around them. The dispositions have a structure which reflects that of the corresponding habitat in which they are formed. The habitat is not merely a milieu but a position within a wider field of social relations, including relations of both similar and different others, for example to members of both the same and different gender and class. Habituation to this location within structures of social relations and material conditions produces a corresponding structure of dispositions which is attuned to them'. ${ }^{96}$

\section{REFERENCES}

1. Kendall E, Rogers A. Extinguishing the social? State sponsored self-care policy and the Chronic Disease Self-management Programme. Disabil Soc 2007; 22: 129-43.

2. Protheroe J, Rogers A, Kennedy A, Macdonald W, Lee V. Promoting patient engagement with selfmanagement support information: a qualitative meta-synthesis of processes influencing uptake. Implement Sci 2008; 3: 44.

3. Blakeman T, Macdonald W, Bower P, Gately C, Chew-Graham C. A qualitative study of GPs' attitudes to self-management of chronic disease. $\mathrm{Br} \mathcal{F}$ Gen Pract 2006; 56: 407-14.

4. Macdonald W, Rogers A, Blakeman T, Bower P. Practice nurses and the facilitation of selfmanagement in primary care. $\mathcal{F}$ Adv Nurs 2008; 62: 191-99.

5. Rogers A, Kennedy A, Nelson E, Robinson A. Uncovering the limits of patient-centeredness: implementing a self-management trial for chronic illness. Qual Health Res 2005; 15: 224-39.

6. Rogers A, Gately C, Kennedy A, Sanders C. Are some more equal than others? Social comparison in self-management skills training for long-term conditions. Chronic Illn 2009; 5: 305-17.

7. Higgs P, Jones IR, Scambler G. The importance of critical realism for the sociology of health inequalities. In: Carter B, New C, eds. Making realism work: realist social theory and empirical research. London: Routledge, 2004: 91-110.

8. Bhaskar R. A realist theory of science. Sussex: Harvester Press, 1975.

9. Sayer A. Method in social science. London: Routledge, 1992. 
10. Archer M, Bhaskar R, Collier A, Lawson T, Norrie A. Critical realism: essential readings. London: Routledge, 1998.

11. Rich M, Taylor S, Chalfen R. Illness as a social construct: understanding what asthma means to the patient to better treat the disease. $\mathcal{F} t \operatorname{Comm} \mathcal{F}$ Qual Improv 2000; 26: 244-53.

12. Scambler G. Sociology, social structure and healthrelated stigma. Psychol Health Med 2006; 11: 288-95.

13. Pawson R, Greenhalgh T, Harvey G, Walshe K. Realist review - a new method of systematic review designed for complex policy interventions. $\mathcal{F}$ Health Serv Res Policy 2005; 10: 21-34.

14. Dixon-Woods M, Cavers D, Agarwal S, et al. Conducting a critical interpretative synthesis of the literature on access to healthcare by vulnerable groups. BMC Med Res Methodol 2006; 6: 35.

15. Noblit G, Hare R. Meta-ethnography: synthesizing qualitative studies. London: Sage, 1988.

16. Pescosolido B. The role of social networks in the lives of persons with disabilities. In: Albrecht G, Seelman K, Bury B, eds. Handbook of disability studies. London: Sage, 2001: 468-90.

17. Cornford C, Cornford H. 'I am only here because of my family' A study of lay referral networks. $\mathrm{Br} \mathfrak{F}$ Gen Pract 1999; 49: 617-20.

18. Walter FM, Emery J, Braithwaite D, Marteau T. Lay understanding of familial risk of common chronic diseases: a systematic review and synthesis of qualitative research. Ann Fam Med 2004; 2: 583-94.

19. Furstenberg A, Davis L. Lay consultation of older people. Soc Sci Med 1984; 18: 827-37.

20. Cleak H, Howe J. Social networks and use of social supports of minority elders in East Harlem. Soc Work Health Care 2003; 38: 19-38.

21. Sunday J, Eyles J, Upshur R. Applying Aristotle's doctrine of causation to Aboriginal and biomedical understandings of diabetes. Cult Med Psychiatry 2001; 25: 63-85.

22. Lawton J, Ahmad N, Peel E, Hallowell N. Contextualising accounts of illness: notions of responsibility and blame in white and South Asian respondents' accounts of diabetes causation. Sociol Health Illn 2007; 29: 891-906.

23. Scollan-Koliopoulos M, O'Connell KA, Walker E. Legacy of diabetes and self-care behaviour. Res Nurs Health 2007; 30: 508-17.

24. Lobchuk M, Murdoch T, McClement S, McPherson C. A dyadic affair who is to blame for causing and controlling the patient's lung cancer? Cancer Nurs 2008; 31: 435-43.

25. Rogge M, Greenwald M, Golden A. Obesity, stigma, and civilized oppression. Adv Nurs Sci 2004; 27: 301-15.

26. Macdonald LD, Anderson HR. Stigma in patients with rectal cancer: a community study. F Epidemiol Community Health 1984; 38: 284-90.
27. Gallant M, Spitze G, Prohaska T. Help or hindrance? How family and friends influence chronic illness self-management among older adults. Res Aging 2007; 29: 375-409.

28. Fiori K, Antonucci T, Cortina K. Social network typologies and mental health among older adults. f Gerontol 2006; 61: 25-32.

29. Strauss A. Work and the division of labor. Sociol $Q$ 1985; 26: 1-19.

30. Gregory S. Living with chronic illness in the family setting. Sociol Health Illn 2005; 27: 372-92.

31. Chesla C, Chun K. Accommodating type 2 diabetes in the Chinese American family. Qual Health Res 2005; 15: 240-55.

32. Beaulieu M. Meanings of chronic fatigue syndrome to friends and families of sufferers. Washington DC: American Sociological Association, 1995.

33. Fisher L, Chesla C, Skaff M, et al. The family and disease management in Hispanic and EuropeanAmerican patients with type a diabetes. Diabetes Care 2000; 23: 267-72.

34. Hanson C, DeGuire M, Schinkel A, Kolterman O. Empirical validation of a family-centred model of care. Diabetes Care 1995; 18: 1347-56.

35. Mackey E, Streisand R. Brief report: the relationship of parental support and conflict to physical activity in preadolescents with Type 1 Diabetes. f Pediatr Psychol 2008; 33: 1137-41.

36. Hepworth J. Gender and the capacity of women with NIDDM to implement medical advice. Scand F Public Health 1999; 27: 260-66.

37. Van Boemel G, Lee P. Effects of adherence to traditional female sex roles on compliance with diabetic regimens: a case history. $\mathcal{F}$ Vis Impair Blind 1999; 93: 17-25.

38. Wong M, Gucciardi E, Li L, Grace S. Gender and nutrition management in type 2 diabetes. Can $\mathcal{F}$ Diab Pract Res 2005; 66: 215-20.

39. Boutin-Foster C. In spite of good intentions: patients' perspectives on problematic social support interactions. Health Qual Life Outcomes 2005; 3: 52 .

40. Bloor M. Observations of abortive illness behaviour. Urban Life 1985; 14: 300-16.

41. Wellman B, Kelner M, Wigdor B. Older adults' use of medical alternative care. $\mathcal{F}$ Appl Gerontol 2001; 20: 3-23.

42. Schilling L, Scatena L, Steiner J, et al. The third person in the room: Frequency, role, and influence of companions during primary care medical encounters. F Fam Pract 2002; 51: 685-90.

43. Clayman M, Roter D, Wissow L, BandeenRoche K. Autonomy-related behaviors of patient companions and their effect on decision-making activity in geriatric primary care visits. Soc Sci Med 2004; 60: 1583-91.

44. Eggly S, Penner L, Greene M, Harper F, Ruckdeschel J, Albrecht T. Information seeking 
during "bad news" oncology interactions: question asking by patients and their companions. Soc Sci Med 2006; 63: 2947-85.

45. Wolff JL, Roter DL. Hidden in plain sight: medical visit companions as a resource for vulnerable older adults. Arch Intern Med 2008; 168: 1409-15.

46. Furler J, Walker C, Blackberry I, et al. The emotional context of self-management in chronic illness: a qualitative study of the role of health professional support in the self-management of type 2 diabetes. BMC Health Serv Res 2008; 8: 214.

47. Ishikawa H, Roter D, Yamazaki Y, Takayama T. Physician-elderly patient-companion communication and roles of companions in Japanese geriatric encounters. Soc Sci Med 2005; 60: 2307-20.

48. Shields C, Epstein R, Fiscella K, et al. Influence of accompanied encounters on patient-centeredness with older patients. F Am Board Fam Pract 2005; 18: 344-54.

49. Rogers A, Nicolaas G. Understanding the patterns and processes of primary care use: a combined quantitative and qualitative approach. Sociol Res Online 1998; 3: U71-87.

50. Cocksedge S, May C. The listening loop: a model of choice about cues within primary care consultations. Med Educ 2005; 39: 999-1005.

51. Adams A, Mah C, Soumerai S, Zhang F, Barton M, Ross-Degnan D. Barriers to self-monitoring of blood glucose among adults with diabetes in an HMO: a cross sectional study. BMC Health Serv Res 2003; 3: 6 .

52. Sin C. Expectations of support among White British and Asian-Indian older people in Britain: the interdependence of formal and informal spheres. Health Soc Care Community 2006; 14: 215-24.

53. Rasmussen B, Dunning P, O’Connell B. Young women with diabetes: using Internet communication to create stability during life transitions. $\mathcal{F}$ Clin Nurs 2007; 16: 17-24.

54. Seeman N. Web 2.0 and chronic illness: new horizons, new opportunities. Healthc $Q$ 2008; 11: 104-10.

55. Kraut R, Patterson M, Lundmark V, Kiesler S, Mukopadhyay T, Scherlis W. Internet paradox: a social technology that reduces social involvement and psychological well-being? Am Psychol 1998; 53: 1017-31.

56. Miller S. The effect of frequency and type of internet use on perceived social support and sense of well-being in individuals with spinal cord injury. Rehabil Couns Bull 2008; 51: 148-58.

57. Loader B, Muncer S, Burrows R, Pleace N, Nettleton S. Medicine on the line? Computermediated social support and advice for people with diabetes. Int 7 Soc Welfare 2002; 11: 53-65.

58. Ravert R, Hancock M, Ingersoll G. Online forum messages posted by adolescents with type 1 diabetes. Diabetes Educ 2004; 30: 827-34.
59. May C, Finch T. Implementing, embedding, and integrating practices: an outline of normalization process theory. Sociology 2009; 43: 535-54.

60. Meier A, Lyons E, Frydman G, Forlenza M, Rimer B. How cancer survivors provide support on cancer-related internet mailing lists. $\mathcal{F} \mathrm{Med}$ Internet Res 2007; 9: e12.

61. Glasgow R, Boles S, Mckay H, Feil E, Barrere M. The D-Net diabetes self-management program: long-term implementation, outcomes, and generalization results. Prev Med 2003; 36: 410-9.

62. Seale C, Ziebland S, Charteris-Black J. Gender, cancer experience and internet use: a comparative keyword analysis of interviews and online cancer support groups. Soc Sci Med 2006; 62: 2577-90.

63. Wenger C. Social networks and the prediction of elderly people at risk. Aging Ment Health 1997; 1: 311-20.

64. DuPertius L, Aldwin C, Bosse R. Does the source of support matter for different health outcomes? f Aging Health 2001; 13: 494-510.

65. Fiori K, Smith J, Antonucci T. Social network types among older adults: a multidimensional approach. f Gerontol 2007; 62B: 322-30.

66. Cattell V. Poor people, poor places, and poor health: the mediating role of social networks and social capital. Soc Sci Med 2001; 52: 1501-16.

67. Putnam RD. Bowling alone: America's declining social capital. F Democr 1995; 6: 65-78.

68. Gambetta D, ed. Trust: making and breaking cooperative relations. Oxford: Basil Blackwell, 1988.

69. Fine B. Social capital versus social theory: political economy and social science at the turn of the millennium. London and New York: Routledge, 2001.

70. Fisher L, Chesla C, Chun K, Skaff M, Mullan J, Kanter R. Patient-appraised couple emotion management and disease management among Chinese American patients with type 2 diabetes. 7 Fam Psychol 2004; 18: 302-10.

71. Ellis D, Templin T, Naar-King S, et al. Family mediators and moderators of treatment outcomes among youths with poorly controlled type 1 diabetes: results from a randomized controlled trial. f Pediatr Psychol 2007; 32: 194-205.

72. Beverley E, Wray L. The role of collective efficacy in exercise adherence: a qualitative study of spousal support and Type 2 diabetes management. Health Educ Res 2008.

73. Roberto K, Gigliotti C, Husser E. Older women's experiences with multiple health conditions: daily challenges and care practices. Health Care Women Int 2005; 26: 672-92.

74. van Dam $H$, van der Horst F, Knoops L, Ryckman R, Grebolder H, van der Borne B. Social support in diabetes: systematic review of controlled intervention studies. Patient Educ Couns 2005; 59: 1-12. 
75. Sayer A. Contributive justice and meaningful work. Res Publica 2009; 15: 1-16.

76. Bourdieu P. Distinction: a social critique of the judgement of taste, London: Routledge, 1984.

77. Schutz A, Luckmann T. The structures of the lifeworld, London: Heinemann, 1973.

78. Granovetter M. Strength of weak ties. Am F Sociol 1973; 78: 1360.

79. Granovetter $M$. The strength of weak ties: a network theory revisited. Sociol Theory 1983; 1: 201-33.

80. Pescosolido B. Beyond rational choice: the social dynamics of how people seek help. Am $\mathcal{f}$ Sociol 1992; 97: 1096-138.

81. Pescosolido B, Rubin B. The web of group affiliations revisited: social life, postmodernism, and sociology. Am Sociol Rev 2000; 65(1): 52-76.

82. Stoller E, Wisniewski A. The structure of lay consultation networks: managing illness in community settings. F Aging Health 2003; 15: 482-507.

83. Bott E. Family and social network: roles, norms and external relationships in ordinary urban families, London: Tavistock, 1957.

84. Phillipson C, Bernard M, Phillips J, Ogg J. The family and community life of older people: social networks and social support in three urban areas, London: Routledge, 2001.

85. Pahl R, Spencer L. Personal communities: not simply families of 'Fate' or 'Choice'. Curr Sociol 2004; 52: 199-221.

86. Strauss A, Fagerhaugh S, Suczek B, Wiener C. Sentimental work in the technologized hospital. Sociol Health Illn 1982; 4: 254-78.

87. Corbin J, Strauss A. Managing chronic illness at home: three lines of work. Qual Sociol 1985; 8: 224-47.

88. Corbin J, Strauss A. Unending work and care: managing chronic illness at home, London: JosseyBass, 1988.

89. Department of Health. Self-care - a real choice: selfcare support - a practical option, London: Department of Health, 2005.

90. Storrs D. Critical literacy among the working poor: individualism and pseudostructural interpretive narratives of health inequalities. Sociol Perspect 2007; 50: 79-100.

91. Borovoy A, Hine J. Managing the unmanageable: elderly Russian Jewish emigrés and the biomedical culture of diabetes care. Med Anthropol $Q 2008 ; 22$ : $1-26$.

92. Blaxter M. Whose fault is it? People's own conceptions of the reasons for health inequalities. Soc Sci Med 1997; 44: 747-56.

93. Corbin J, Strauss A. The articulation of work through interaction. Soc Quart 1993; 34: 71-83.
94. Bury M. Chronic disease as a biographical disruption. Sociol Health Illn 1982; 4: 167-182.

95. Star SL, Strauss A. Layers of silence, arenas of voice: the ecology of visible and invisible work. Comput Support Coop Work 1999; 8: 9-30.

96. Sayer A. The moral significance of class, Cambridge: Cambridge University Press, 2005.

97. Bolam B, McLean C, Pennington A, Gillies P. Using new media to build social capital for health: a qualitative process evaluation study of participation in the CityNet project. F Health Psychol 2006; 11: 297-308.

98. Fowler J, Christakis N. Dynamic spread of happiness in a large social network: longitudinal analysis over 20 years in the Framingham Heart Study. BMF 2008: 337: a2338.

99. Grace C, Begum R, Subhani S, Kopelman P, Greenhalgh T. Prevention of type 2 diabetes in British Bangladeshis: qualitative study of community, religious, and professional perspectives. $B M \mathcal{F}$ 2008; 337: a1931.

100. Hains A, Berlin K, Davies W, Sato A, Smothers M, Clifford L, Alemzadeh R. Attributions of teacher reactions to diabetes self-care behaviors. $\mathcal{F}$ Pediatr Psychol 2009; 34: 97-107.

101. Helgeson V, Reynolds K, Escobar O, Siminerio L, Becker D. The role of friendship in the lives of male and female adolescents: does diabetes make a difference? F Adolescent Health 2007; 40: 36-43.

102. Hjelm K, Bertero C. Social support as described by Swedish people diagnosed with type 2 diabetes mellitus. Prim Health Care Res Dev 2009; 10: 26-37.

103. Law C. Dissimilarity in adolescent and maternal representations of type 1 diabetes: exploration of relations to adolescent well-being. Child 2002; 28: 369-78.

104. Penninx B, van Tilburg T, Kriegsman D, Boeke AJ, Deeg D, van Eijk J. Social network, social support, and loneliness in older persons with different chronic diseases. F Aging Health 1999; 11: 151-68.

105. Rasmussen B, Dunning T, Cox H, O Connell B. The mother-daughter guilt dynamic: effects of type 1 diabetes during life transitions. $\mathcal{F}$ Clin Nurs 2008; 17: 380-89.

106. Trento M, Passera P, Tomalino M, et al. Group visits improve metabolic control in type 2 diabetes. Diabetes Care 2001; 24: 995-1000.

107. Vickers K, Nies M, Patten C, Dierkhising R, Smith S. Patients with diabetes and depression may need additional support for exercise. Am $\mathcal{F}$ Health Behav 2006; 30: 353-62. 


\section{APPENDIX}

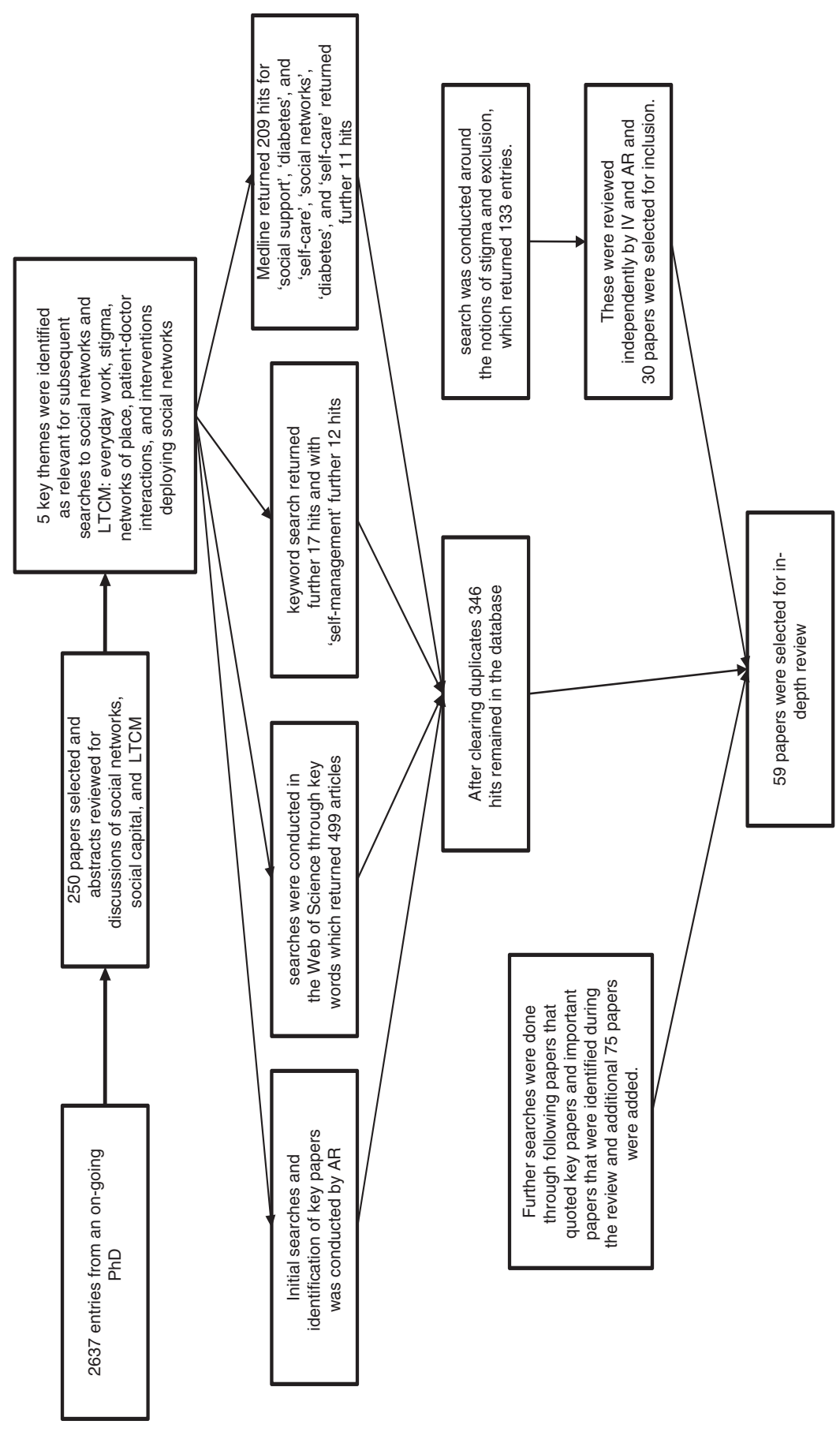

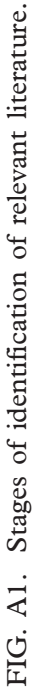




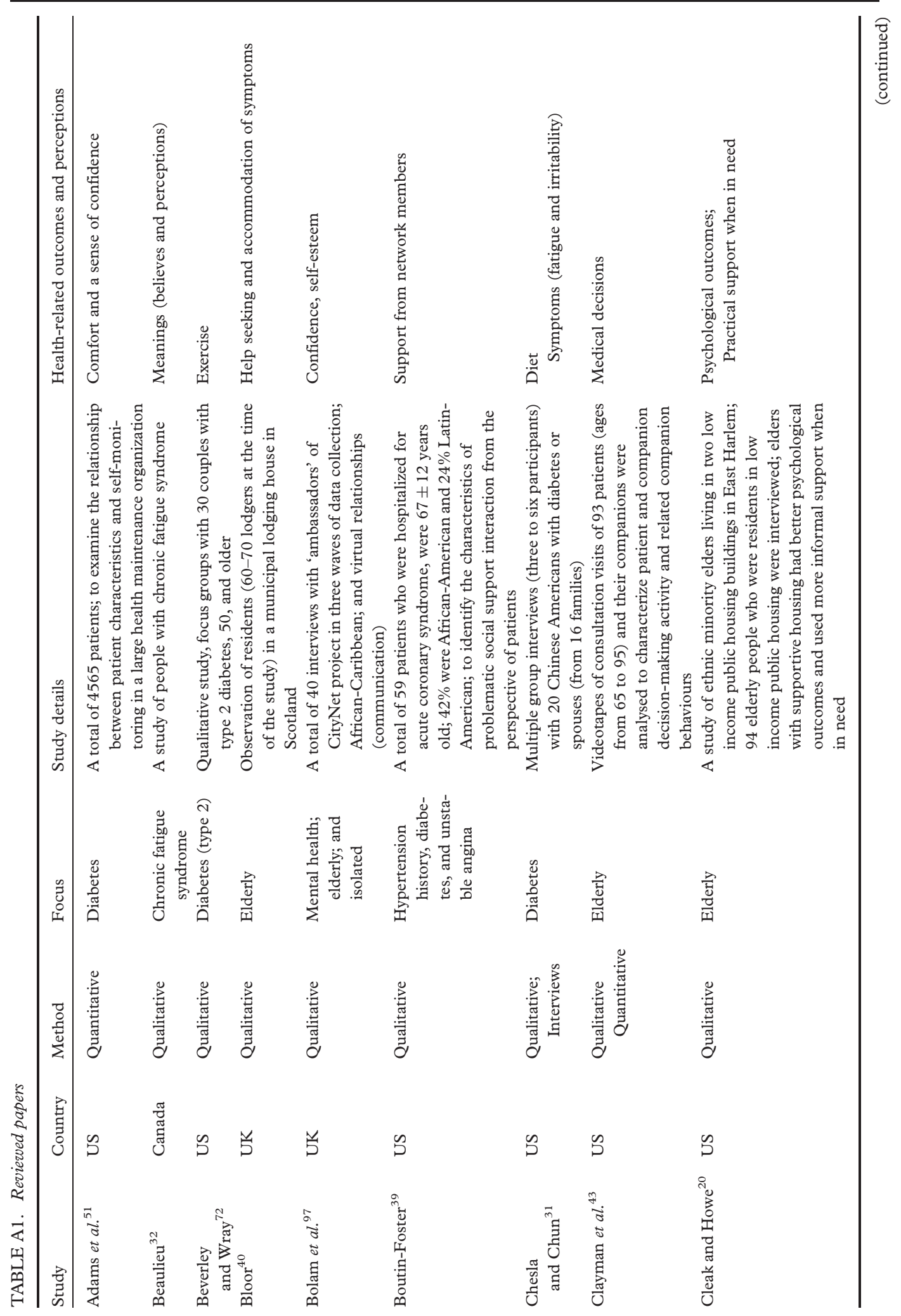




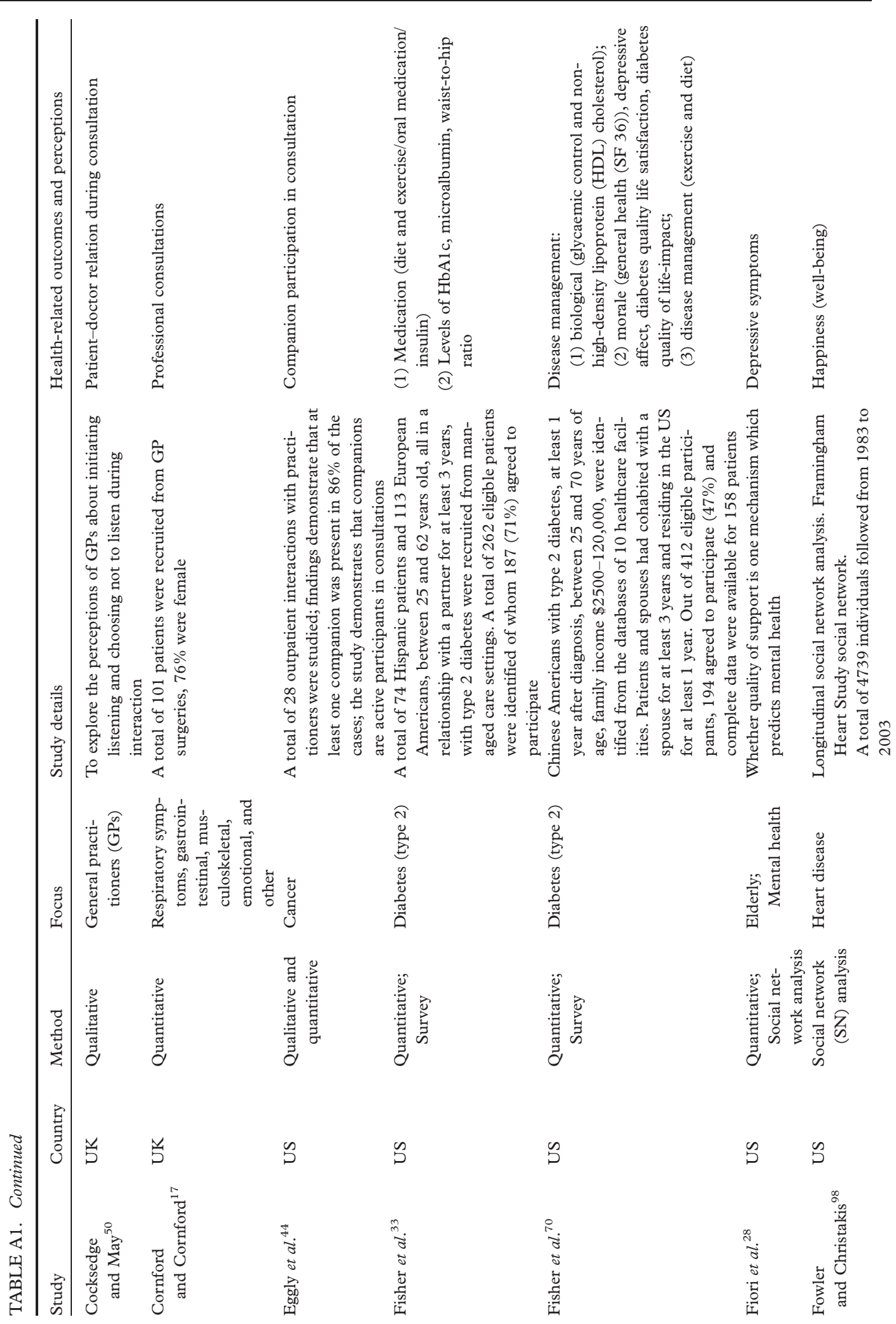



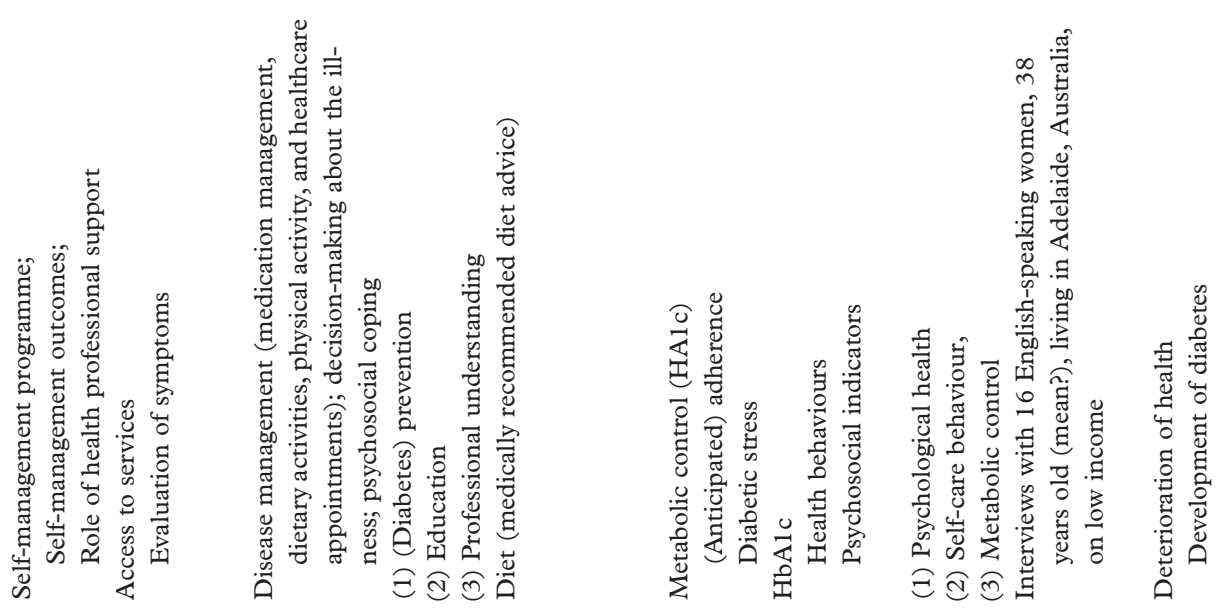

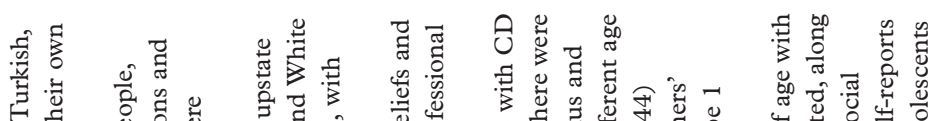

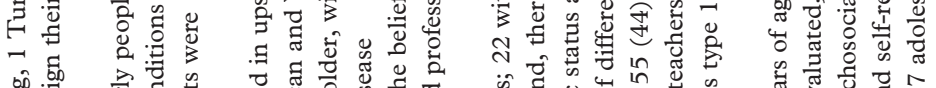

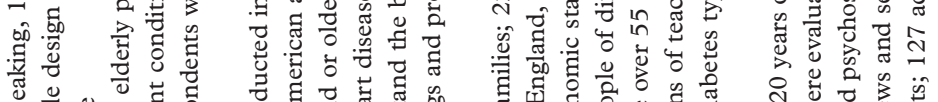

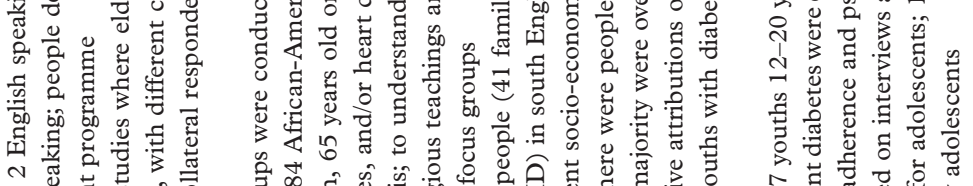

N

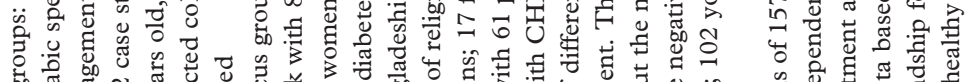

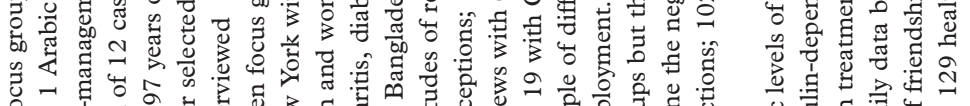

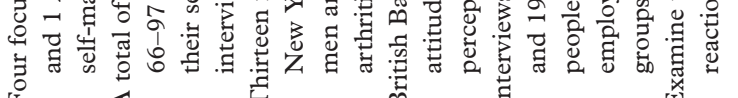

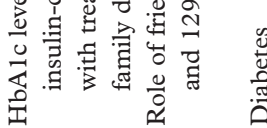

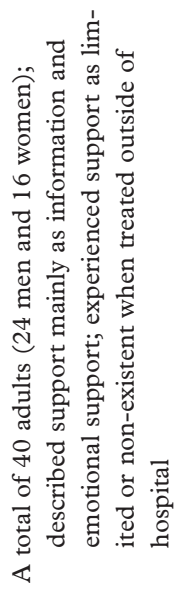

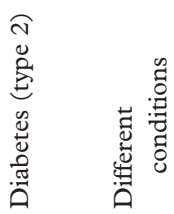

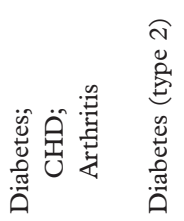

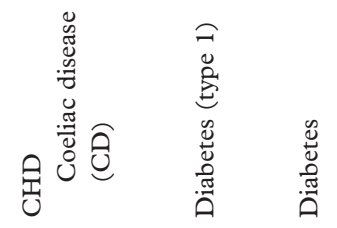

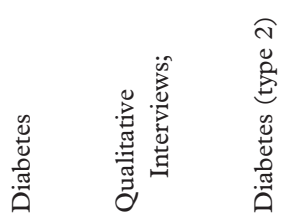

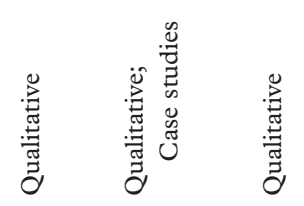

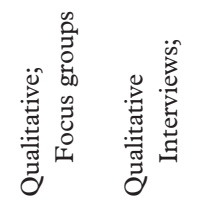

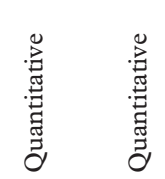

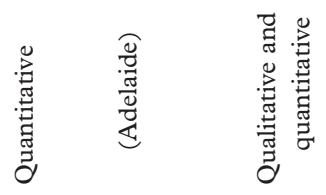

袢

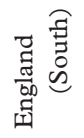

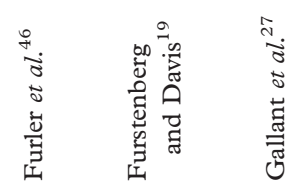

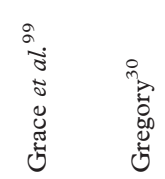

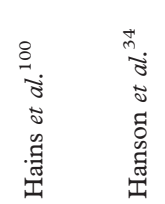

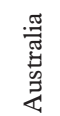

苛

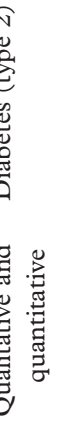

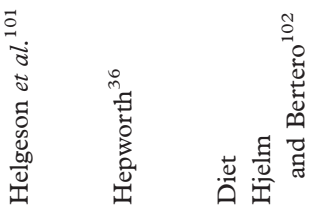




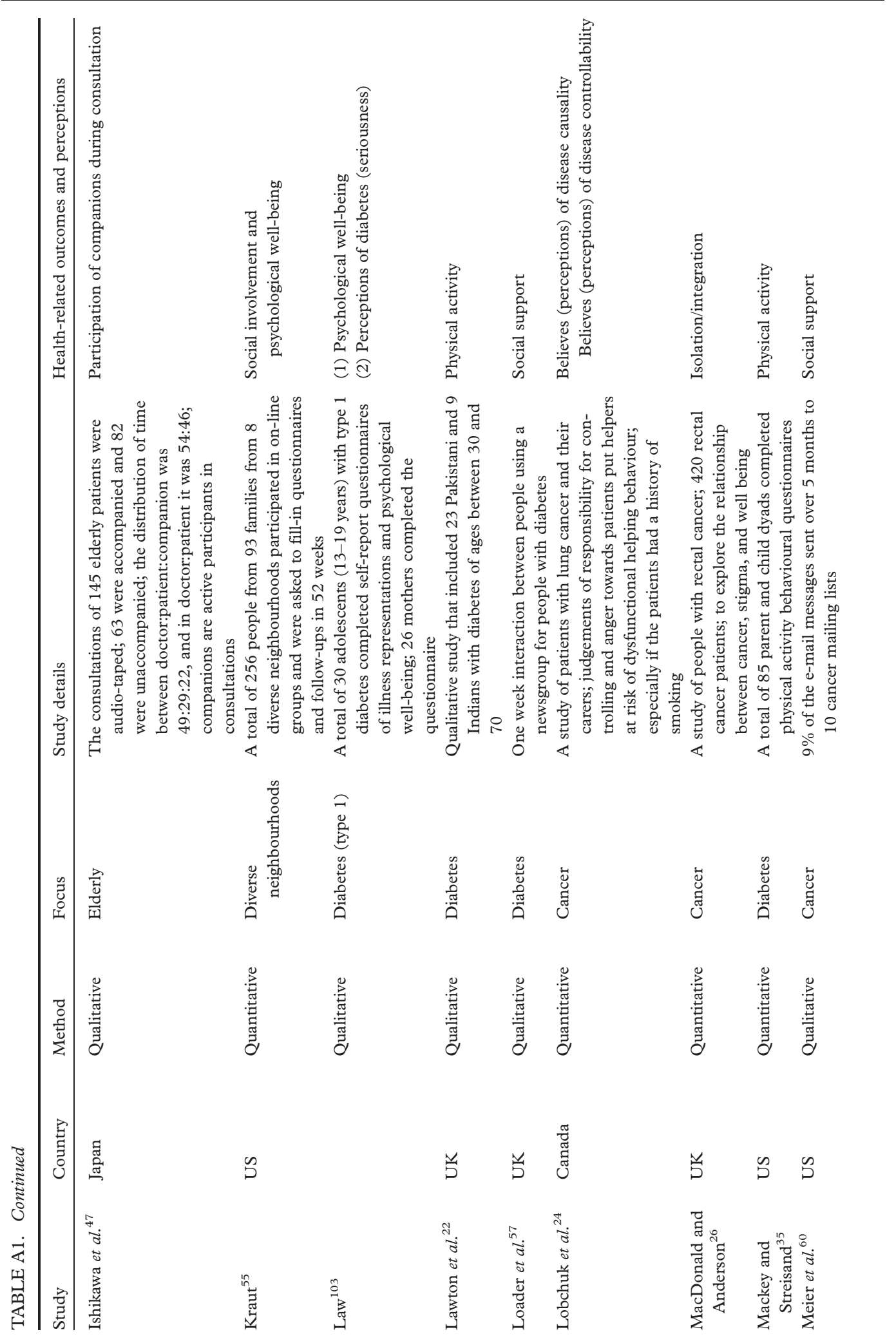



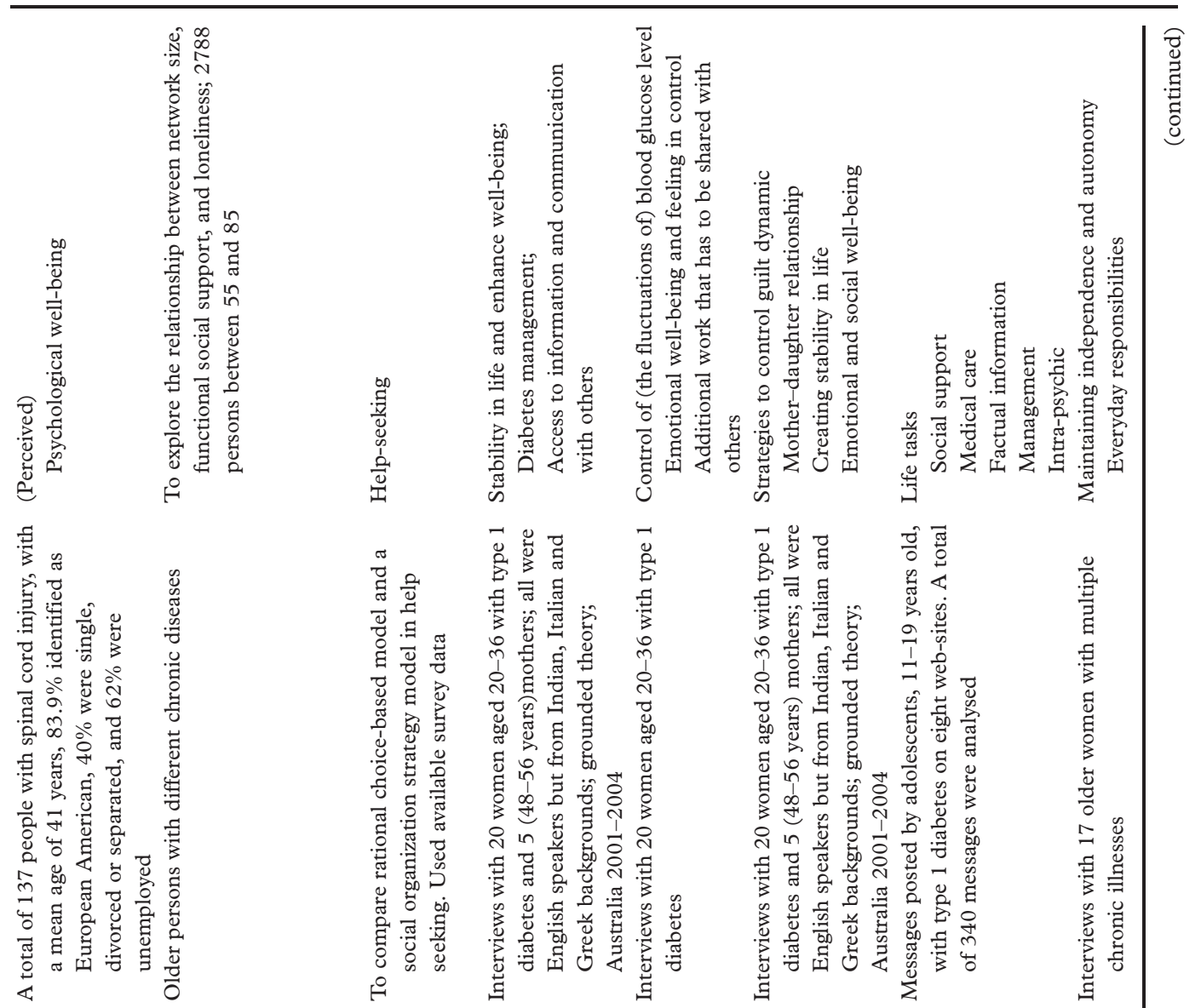

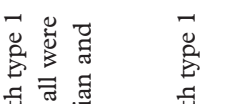
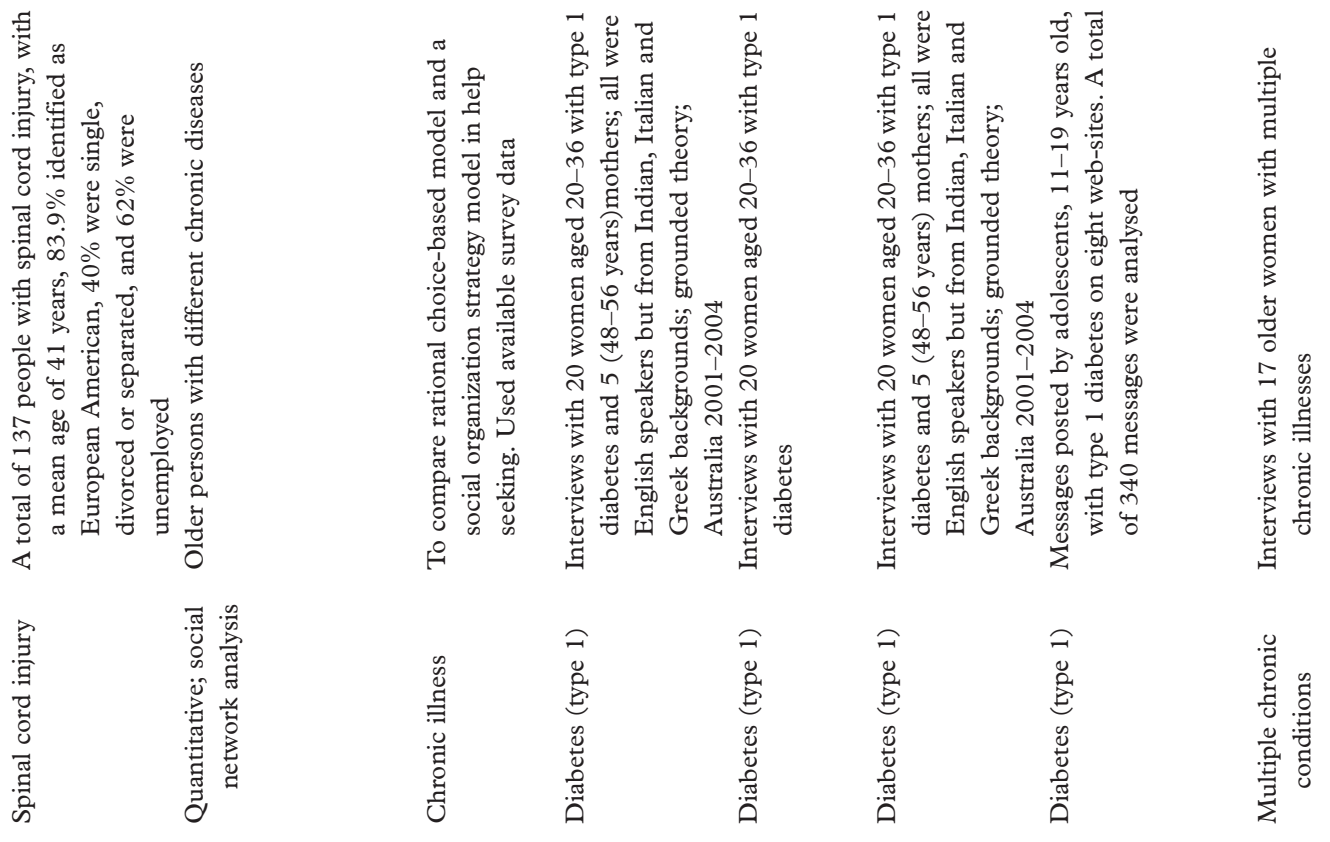

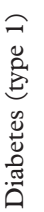
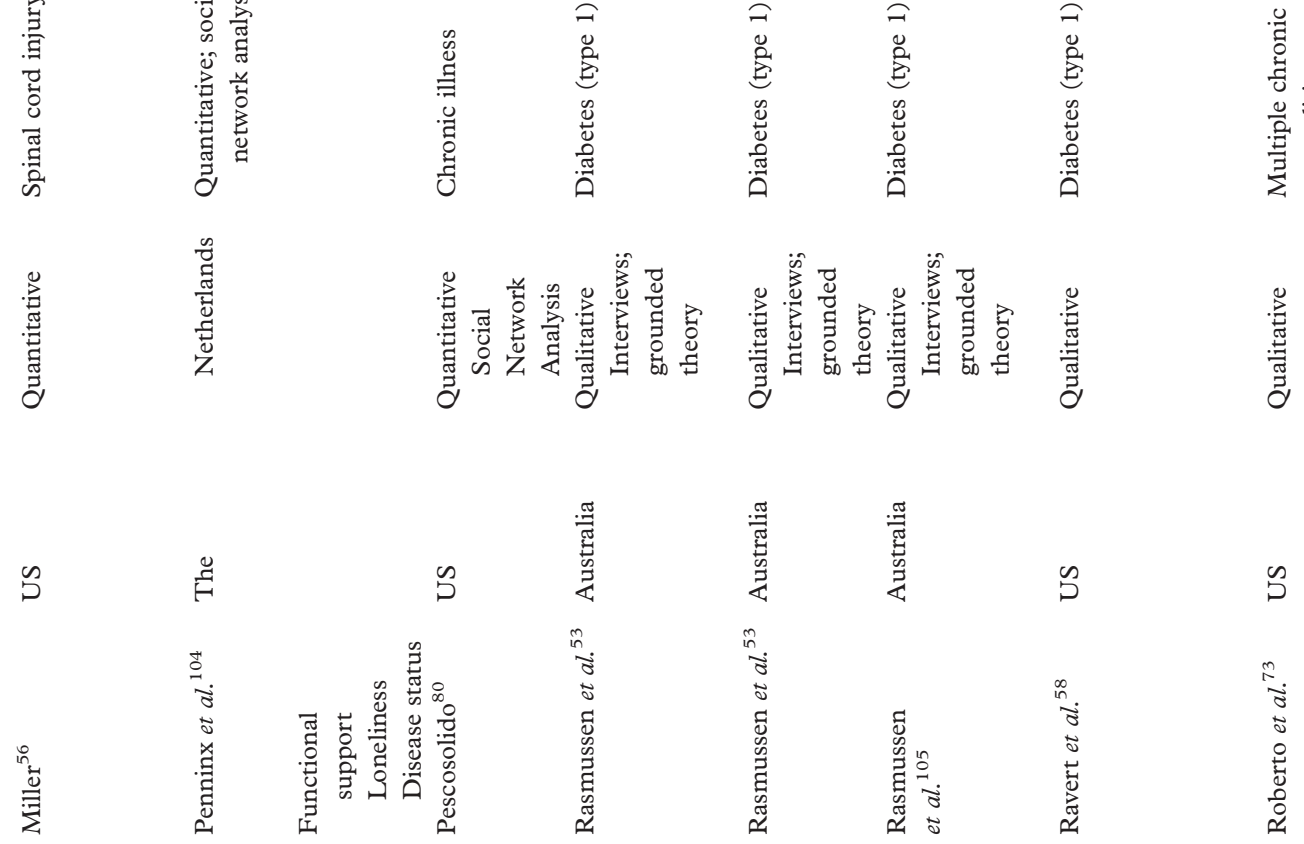


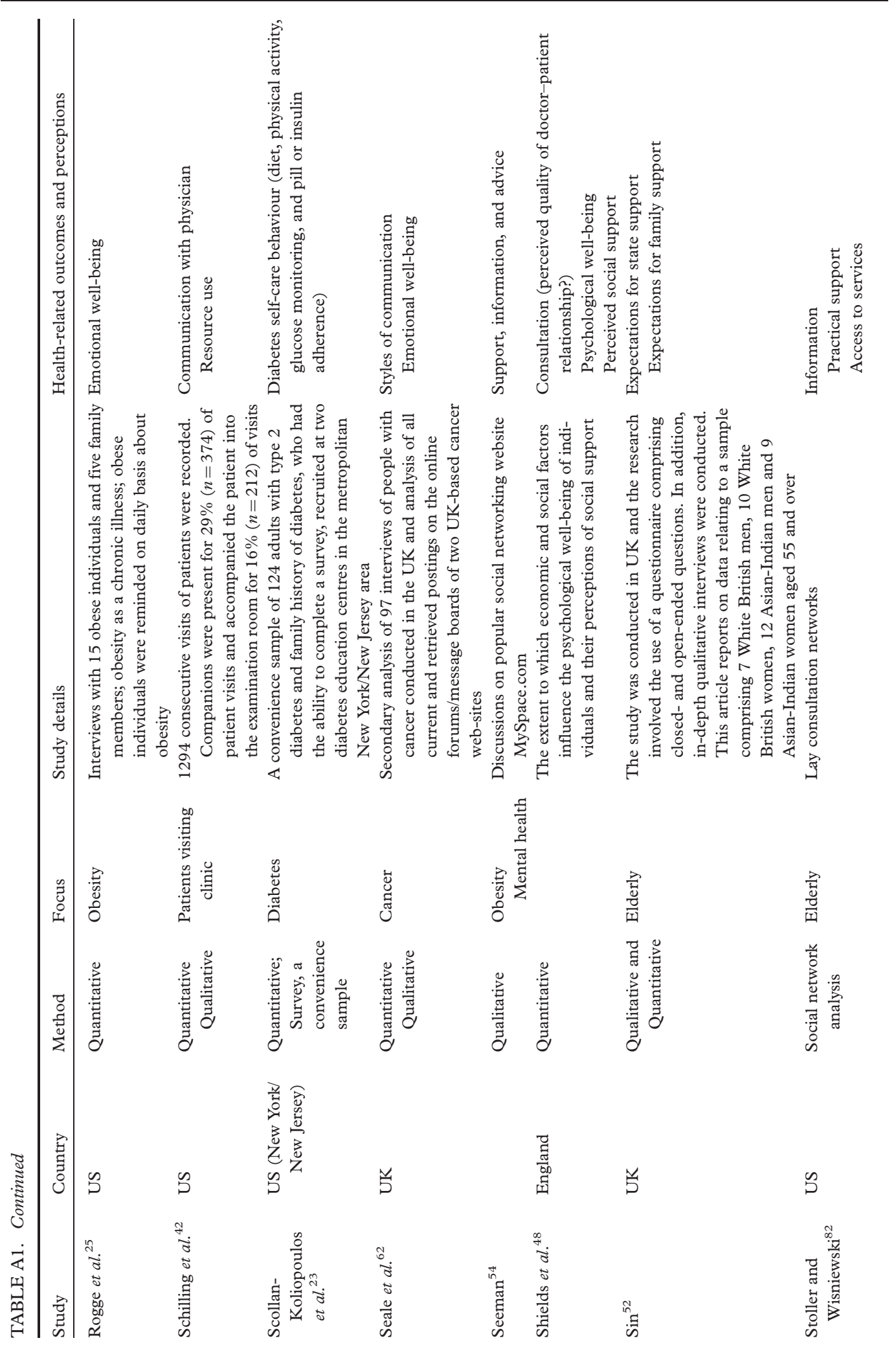




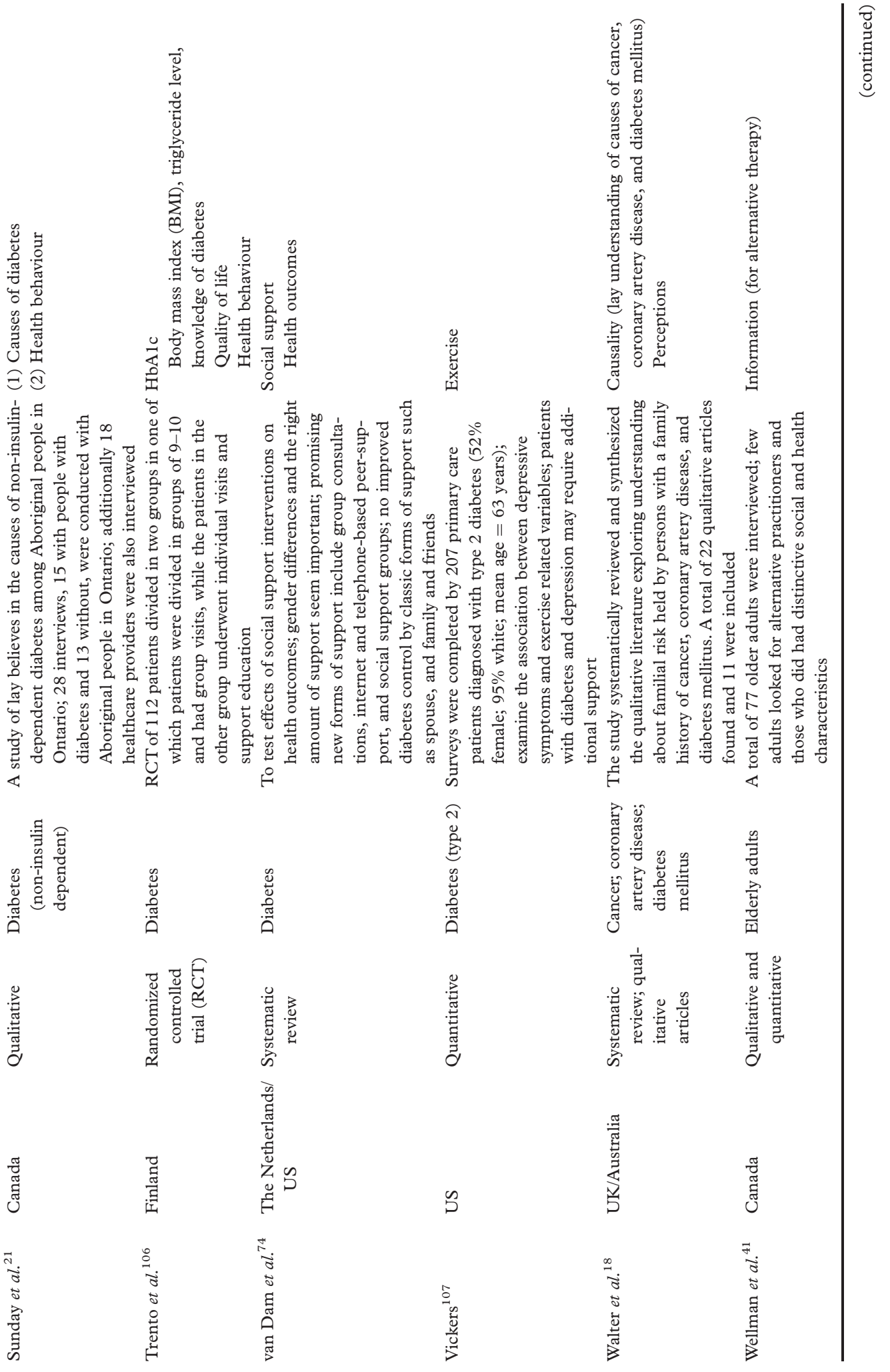




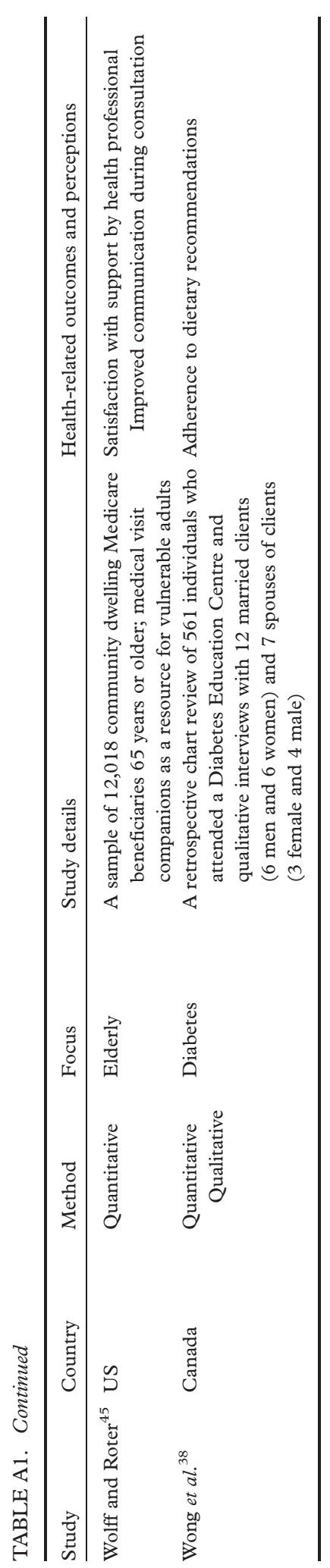

